\title{
Towards efficient terpenoid biosynthesis: manipulating IPP and DMAPP supply
}

\author{
Qin Wang ${ }^{1}$, Shu Quan ${ }^{2}$ and Han Xiao ${ }^{1 *}$ (D)
}

\begin{abstract}
Terpenoids are a group of largest natural products with important biological functions, and their efficient biosynthesis is of particular importance to both academia and industry. As the building blocks for terpenoid biosynthesis, a suitable supply of isopentenyl diphosphate (IPP) and dimethylallyl diphosphate (DMAPP) is extremely crucial for efficient terpenoid biosynthesis. With this focus, we first introduce biosynthetic pathways of IPP and DMAPP, and then summarize the current strategies adopted for manipulating IPP and DMAPP supply. At last, how to further manage IPP and DMAPP supply to improve terpenoid biosynthesis is also proposed.
\end{abstract}

Keywords: Terpenoid, Mevalonate pathway, 2-C-Methyl-D-erythritol 4-phosphate (MEP), Isopentenyl diphosphate (IPP), Dimethylallyl diphosphate (DMAPP), Biosynthesis

\section{Introduction}

Terpenoids are a class of natural products with diverse structures and essential biological functions (Schrader and Bohlmann 2015; Tarkowska and Strnad 2018). For example, animal-derived terpenoids (e.g., cholesterol, dolichol, ubiquinone) are involved in cell membranes formation, glycoproteins biosynthesis and intracellular electron transport (Goldstein and Brown 1990). Plantderived terpenoids (e.g., tocopherol, brassinolide, and gibberellin) are responsible for the regulation of cell growth and defense (Piironen et al. 2000; Tholl 2015). In addition, many commercially useful compounds (e.g., pharmaceuticals, flavorings, biofuel) belong to terpenoid (Ajikumar et al. 2008; Immethun et al. 2013; Tippmann et al. 2013). Therefore, efficient biosynthesis of terpenoid is receiving great interests from researchers (Bian et al. 2017).

According to the number of C5 units involved during their synthesis, terpenoids are classified as hemiterpenoid (C5), monoterpenoid (C10), diterpenoid

\footnotetext{
*Correspondence: smallhan@sjtu.edu.cn

1 State Key Laboratory of Microbial Metabolism, Joint International Research Laboratory of Metabolic \& Developmental Sciences, and Laboratory of Molecular Biochemical Engineering, School of Life Sciences and Biotechnology, Shanghai Jiao Tong University, 800 Dong-chuan Road, Shanghai 200240, China

Full list of author information is available at the end of the article
}

(C20), triterpenoid (C30), tetraterpenoid (C40), and polyterpenoid (>C40) (Connolly and Hill 1991). Formation of terpenoid usually undergoes a continuous head-to-tail addition of its building blocks, which are isoprene diphosphate (IPP) and its isomer dimethylallyl diphosphate (DMAPP) (Karine et al. 2012; Laskovics and Poulter 1981). First, a head-to-tail condensation of IPP and DMAPP produces geranyl diphosphate (GPP), the precursor of monoterpenoid. Then, the successive addition of IPP results in the formation of precursors of sesquiterpenoid and diterpenoid, which are farnesyl diphosphate (FPP) and geranylgeranyl diphosphate (GGPP), respectively. On this basis, two molecules of FPP and GGPP are, respectively, head-to-head condensed to form squalene and phytoene, the precursors of triterpenoid and tetraterpenoid. These linearized precursors are further subjected to cyclization and post modifications (e.g., oxidation, acetylation) to form various terpenoids (Luthra et al. 1999; Mcgarvey and Croteau 1995).

Although IPP and DMAPP are the crucial requisite to efficient terpenoid biosynthesis, their accumulation is harmful to cell growth and can affect terpenoid production in turn (George et al. 2018; Martin et al. 2003; Sivy et al. 2011). As a result, a suitable supply of IPP and DMAPP is of great importance to efficient terpenoid biosynthesis. Other than providing a comprehensive view of achieving efficient terpenoid biosynthesis based on 
one individual enzyme (Liao et al. 2014) or a particular biosynthetic pathway (Liao et al. 2016), we focus on summarizing the strategies of manipulating IPP and DMAPP supply in this review, including important and recent works which can reflect the latest progress. We also propose several strategies for further improving terpenoid biosynthesis regarding managing IPP and DMAPP supply.

\section{Biosynthesis of IPP and DMAPP}

IPP and DMAPP are mainly synthesized via two pathways: the mevalonate (MVA) pathway (Liao et al. 2016) and the non-mevalonate pathway, which is also known as the 2-C-methyl-D-erythritol 4-phosphate (MEP) pathway (Rohmer 1999). The MVA pathway mainly exists in the cytoplasm and peroxisome of eukaryotes, while the MEP pathway exists in most bacteria (Boucher and Doolittle 2000; Lange et al. 2000). In addition, plants harbor the MVA pathway in the cytoplasm to form sesquiterpenoid and triterpenoid, and the MEP pathway in plastid to form monoterpenoid, diterpenoid and tetraterpenoid, respectively (Henry et al. 2015; Lichtenthaler 1999; Lichtenthaler et al. 1997).

In the 1950s, the MVA pathway was recognized as the dominant pathway for terpenoid biosynthesis (Little and Bloch 1950). In this pathway, two molecules of acetyl-CoA are condensed to acetoacetyl CoA by acetyl$\mathrm{CoA}$ acetyltransferase (AACT). Acetoacetyl CoA and another molecule of acetyl-CoA are then condensed by hydroxymethylglutaryl-CoA synthase (HMGS) to form 3-hydroxy-3-methylglutaryl-CoA (HMG-CoA), which is further reduced by 3-hydroxy-3-methylglutaryl-CoA reductase (HMGR) to produce mevalonate. After a twostep phosphorylation and decarboxylation catalyzed by mevalonate kinase (MK), phosphomevalonate kinase (PMK), and diphosphomevalonate decarboxylase (MVD), mevalonate is converted into IPP (Bochar et al. 1999), and then, IPP is isomerized to DMAPP by isopentenyl diphosphate isomerase (IDI) (Fig. 1) (Kaneda et al. 2001).

Most archaea were characterized to harbor enzymes of the MVA pathway (Nishimura et al. 2013), and a modified MVA pathway may exist in some archaea lacking PMK and MVD (Vinokur et al. 2014). Initially, Grochowski et al. identified an isopentenyl phosphate kinase (IPK) from Methanocaldococcus jannaschii capable of phosphorylating isopentenyl phosphate (IP) to generate IPP (Grochowski et al. 2006). Later, the phosphomevalonate decarboxylase (MPD) activity has been identified in Chloroflexi bacterium Roseiflexus castenholzii (Dellas et al. 2013) and archaeal extremophile Haloferax volcanii (Vannice et al. 2014). Based on these discoveries, researchers proposed an alternative route to produce IPP (Henry et al. 2015): after formation of 5-phosphomevalonate (MVP), the MPD catalyzes the decarboxylation of MVP to IP, and IPK catalyze the phosphorylation of IP to IPP (Fig. 1).

After the 1950s, a growing number of investigations indicated that IPP might not be synthesized merely from the MVA pathway. In one study, the ${ }^{14} \mathrm{C}$-labeled mevalonate was rarely incorporated into the isoprenoids (e.g., carotene) produced in the plastid of maize seedlings, while the cytoplasmic sterols were quickly incorporated (Goodwin 1958). Similar phenomena were also reported in carrot, tomato and oat (Braithwaite and Goodwin 1960a, b; Lichtenthaler et al. 1982). Moreover, the ${ }^{14} \mathrm{C}$-labeled pyruvate and $\mathrm{CO}_{2}$ were rapidly incorporated into plastid-produced isoprenoid in Sinapis alba (LutkeBrinkhaus and Kleinig 1987). Using gas chromatography-mass spectrometry, a series of follow-up studies revealed a mevalonate-independent pathway, the MEP pathway, for IPP biosynthesis (Rodriguez-Concepcion and Boronat 2002; Rohmer 1999; Rohmer et al. 1993; Schwender et al. 1996).

In MEP pathway, pyruvate and glyceraldehyde 3-phosphate (G3P) are condensed by thiamin diphosphatedependent enzyme 1-deoxy-D-xylulose-5-phosphate synthase (DXS) to form 1-deoxy-D-xylulose 5-phosphate (DXP). DXP was reduced by 1-deoxy-D-xylulose-5-phosphate reductoisomerase (DXR) to form MEP (Kuzuyama et al. 1998), which is catalyzed by $2-C$-methyl-D-erythritol 4-phosphate cytidylyltransferase (MCT) to generate 4-(cytidine 5'-diphospho)-2-C-methyl-D-erythritol (CD-ME). After phosphorylation, cyclization and ring opening, CD-ME is converted into 1-hydroxy-2-methyl2-butenyl 4-diphosphate (HMBPP) under the catalysis of 4-diphosphocytidyl-2-C-methyl-D-erythritol kinase (CMK), 2-C-methyl-D-erythritol 2,4-cyclodiphosphate synthase (MDS) and 4-hydroxy-3-methylbut-2-enyldiphosphate synthase (HDS), respectively (Herz et al. 2000) (Fig. 1). Different from the MVA pathway, in which the DMAPP is synthesized via IPP isomerization, the IPP and DMAPP derived from the MEP pathway are directly generated from HMBPP by 4-hydroxy-3-methylbut-2enyl diphosphate reductase (HDR) (Felix et al. 2002).

In 2012, an MEP shunt pathway (5-methylthioadenine (MTA)-isoprene pathway) was characterized to generate IPP and DMAPP in Rhodospirillum rubrum (Erb et al. 2012) (Fig. 1). First, MTA is catalyzed by MTA phosphorylase (MtnP) to form 5-methylthio-D-ribose1-phosphate (MTR-1P), followed by an isomerization to generate 5-methylthio-D-ribulose-1-phosphate (MTRu1P) by MTR-1P isomerase (MtnA). Then, MTRu-1P is converted into a mixture of 1-methylthio-ribulose5-phosphate (MTRu-5P) and 1-methylthio-xylulose5-phosphate (MTXu-5P) by MTRu-1P dehydratase, which is a ribulose-1,5-bisphosphate carboxylase/ 


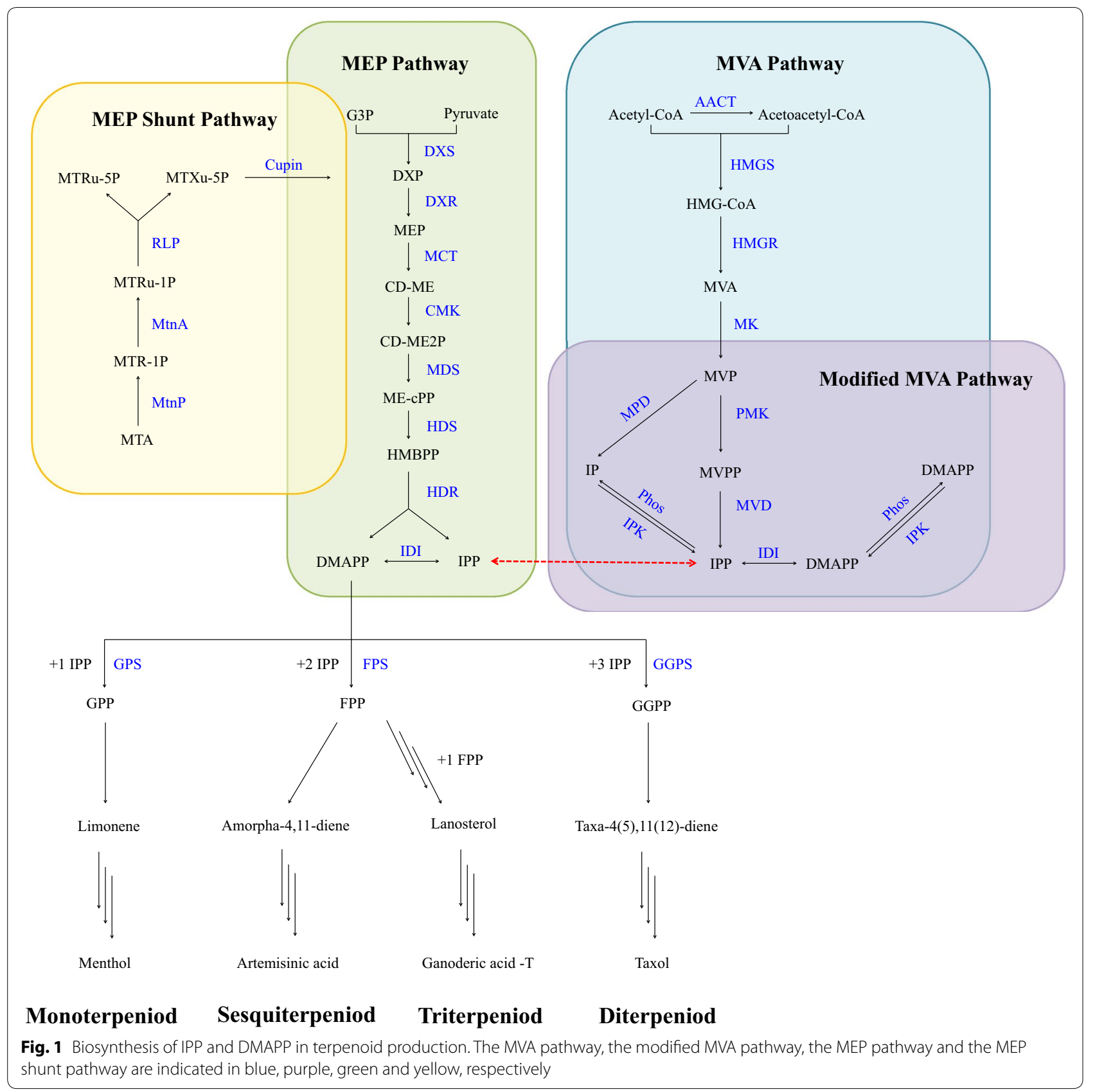

oxygenase (RubisCO)-like protein (RLP) (Imker et al. 2008). After that, MTXu-5P is converted into DXP by cupin-type MTXu-5P sulfating enzyme-mediated catalysis, which simultaneously produces mercaptan as a sulfur source for cell growth. The rlp and cupin gene are usually physically close in a cluster. The MEP shunt pathway has been demonstrated to play an important role in generating DXP in $R$. rubrum. In addition to $R$. rubrum, organisms carrying the rlp-cupin cluster were predicted to have the MEP shunt pathway, such as
Rhodopseudomonas, Rhodomicrobium, and Nitrosococcus. As confirmed in a recent study, the MEP shunt pathway has been detected in Rhodopseudomonas palustris under aerobic cultivation (Miller et al. 2018).

\section{Manipulating the supply of IPP and DMAPP to enhance terpenoid biosynthesis}

A sufficient supply of IPP and DMAPP is the basic premise for terpenoids biosynthesis (Formighieri and Melis 2014). However, an excessive level of IPP and DMAPP 
may cause impaired cell growth and accordingly limit terpenoid production (George et al. 2018; Sivy et al. 2011). Thus, manipulating the supply of IPP and DMAPP is of particular importance for terpenoid biosynthesis. To achieve it, strategies including rewiring the central metabolic pathway, overcoming the rate-limiting step, introducing heterologous pathway, enhancing interaction between different biosynthetic pathways, alleviation of the toxicity of IPP and DMAPP, as well as discovering or engineering downstream enzymes by exploration of the toxicity of IPP and DMAPP will be thoroughly discussed in this part.

\section{Rewiring the central metabolic pathway}

The initial substrates for IPP and DMAPP biosynthesis, including acetyl-CoA, G3P and pyruvate, are generated via the central metabolic pathway. Rewiring central carbon flux towards these substrates allows increased production of IPP, DMAPP and downstream terpenoids. To block the formation of acetic acid from acetyl-CoA and direct more carbon flux into IPP synthesis, the gene cluster ackA-pta was disrupted in Escherichia coli. As expected, the acetate production was greatly reduced in the resultant mutant and the lycopene production was $45 \%$ higher than the original strain (Vadali et al. 2005). As compared to the glycolytic pathway, the generation of acetyl-CoA from the pyruvate dehydrogenase bypass pathway is more efficient (Pronk et al. 1996). Overexpression of pyruvate dehydrogenase, acetaldehyde dehydrogenase, and acetyl-CoA synthetase encoding genes led to increased production of mevalonate, IPP, and amorphadiene (Shiba et al. 2007) (Fig. 2a).
Supplying equal molar of G3P and pyruvate is required for DMAPP and IPP generation via the MEP pathway. At the end of glycolysis, conversion of G3P into phosphoenolpyruvate (PEP) is achieved by phosphoglycerate mutase (PGM) and enolase (ENO), followed by formation of pyruvate by pyruvate kinase (PK) (Romano and Conway 1996). Moreover, production of PEP can also be achieved by conversion of either oxaloacetate, an intermediate of TCA cycle, by PEP carboxykinase (PCK) (Clark 1989) or pyruvate by PEP synthase (PPS) (Geerse et al. 1989; Ramseier et al. 1993). On the other hand, the opposite reaction from PEP to pyruvate is catalyzed by the enzymes PykF and PykA (Boiteux et al. 1983; Waygood et al. 1976). As a result, overexpression of PCK and PPS led to the accumulation of PEP, while deletion of PykF and PykA further prevented the conversion of PEP into pyruvate. These metabolic engineering efforts maintained an equal balance between pyruvate and G3P, and successfully improved production of IPP and its downstream product lycopene in E. coli (Farmer and Liao 2001) (Fig. 2b). In a more recent work, five MEP feeding modules derived from four glycolytic pathways in E. coli, which are Embden-Meyerhof pathway (EMP), Entner-Doudoroff pathway (EDP), pentose phosphate pathway (PPP) and Dahms pathway, respectively, were tested for terpenoid production. With simultaneous generation of G3P and pyruvate, the EDP-containing module exhibited significantly higher isoprene titer and yield than that of the EMP-containing module, which provides a new direction to rewire the central metabolism for MEP-dependent terpenoid biosynthesis (Liu et al. 2013).

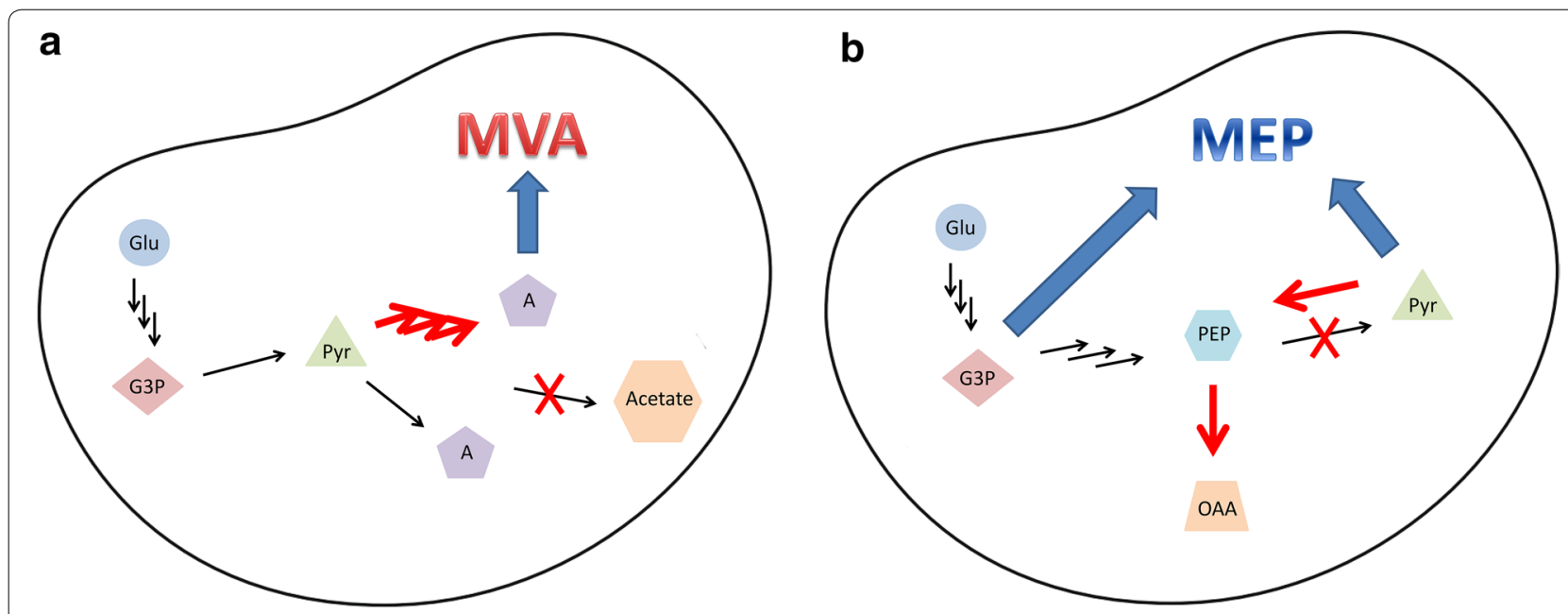

Fig. 2 Rewiring the central metabolic pathway by a increasing the supply of acetyl-CoA and $\mathbf{b}$ balancing the supply of glyceraldehyde 3-phosphate and pyruvate. The bold red arrows indicate overexpression of corresponding enzymes (pathways) and red forks indicate disruption of corresponding enzymes 


\section{Overcoming the rate-limiting step}

Except for providing sufficient initial substrates, overcoming the rate-limiting steps of IPP and DMAPP biosynthesis is not new but an effective approach for increasing their production. In the late 1980s, HMGR was first identified as a rate-limiting enzyme in the MVA pathway (Bach 1986). In that study, the phytosterol contents decreased significantly when their producing hosts were treated with specific competitive inhibitors of HMGR (Bach 1986; Stermer and Bostock 1987), indicating that HMGR activity greatly affected terpenoid biosynthesis. After that, there is increasing evidence to show that HMGR plays a key role in increasing terpenoid yield in plants, yeast and bacteria (Bach 1986; Chappell et al. 1995; Enfissi et al. 2005; Kim et al. 2013; Ma et al. 2011; Stermer et al. 1994; Tsuruta et al. 2009). Overexpression of hamster HMGR in tobacco driven by the cauliflower mosaic virus $35 S$ promoter resulted in an over 100 -fold increase in cycloartenol (a sterol biosynthetic intermediate) and a 2-fold increase in total sterols (Chappell et al. 1995). Two isoenzymes of HMGR, Hmg1p and Hmg2p, were identified in yeast. Although degradation of these Hmg proteins was observed with increased level of intermediates in MVA pathway, Hmg1p was more stable than Hmg2p (Chun et al. 1990; Hampton and Rine 1994). Since numerous studies indicated that overexpression of Hmg1p enhanced the MVA pathway, it is still subjected to feedback inhibition under high level of sterol (Hampton and Rine 1994). To overcome this limitation, the $\mathrm{N}$-terminal domain-truncated Hmg1p (t-HMGR) was constructed. As a result, overexpression of $t$-HMGR led to nearly five times higher production of amorphadiene in Saccharomyces cerevisiae (Ro et al. 2006). This strategy also increased sterol, sitosterol, stigmasterol and artemisinic acid-12- $\beta$-diglucoside production in tobacco, Lavandula latifolia, and Nicotiana benthamiana, respectively (Holmberg et al. 2003; Munoz-Bertomeu et al. 2007; van Herpen et al. 2010). On the other hand, increasing the terpenoid production was also achieved by protein engineering of Hmg2p. For example, a stable variant Hmg2p (K6R) was constructed to counteract cellular ubiquitination, and improved the production of monoterpenoid and sesquiterpenoid (Ignea et al. 2011).

Besides, HMGS manipulation is also considered as an effective engineering strategy for MVA-derived terpenoid production (Liao et al. 2014). A HMGS mutant from Brassica juncea BjHMGS1 (S359A), with tenfold increased specific activity (Nagegowda et al. 2004), was overexpressed in Solanum lycopersium, which improved the production of MVA-derived squalene and phytosterols (Liao et al. 2018). In addition, IPK plays a significant role in the alternative MVA pathway, because it regulates the ratios of IP-IPP and 4-dimethylaminopyridine
(DMAP)-DMAPP (Henry et al. 2015). The IPK homologs have been found in plant genomes (Dellas et al. 2013). Henry et al. confirmed that Arabidopsis thaliana IPK, phosphorylates IP and DMAP (Henry et al. 2015). The contents of campesterol, sitosterol and $\beta$-caryophyllene were reduced in ipk knockdown or knockout $A$. thaliana (Henry et al. 2015). This may be due to a decrease in the content of important precursors, IPP and DMAPP. Later, overexpression of Arabidopsis-derived IPK in tobacco led to increased production of cholesterol, stigmasterol, sitosterol and campesterol (Henry et al. 2015). In a more recent study, overexpression of MPD from Roseiflexus castenholzii in tobacco enabled producing IP from scratch, which introduced another branch of the MVA pathway to increase the metabolic flux towards downstream terpenoids. As a result, a 3.1- and a 6.4-fold increase of monoterpene and sesquiterpene was achieved in this plant, respectively (Henry et al. 2018).

DXS is proved as the first rate-limiting step in MEP pathway (Estevez et al. 2001; Kim et al. 2006; Zhao et al. $2011)$, whose $k_{\text {cat }} / K_{M}$ value is substantially lower than other enzymes in this pathway (Kuzuyama et al. 2000). Increasing DXS activity is recognized as the most effective strategy for terpenoid biosynthesis in many species, such as Synechococcus leopoliensis (Bach and Lichtenthaler 2010; Schwender et al. 1996), Lycopersicon esculentum (Rohmer 1999) and Streptomyces (Kuzuyama et al. 1998). For example, heterologous expression of DXS from Bacillus subtilis improved IPP, DMAPP and $\beta$-carotene production in E. coli (Leonard et al. 2010). To improve enzymatic activity of DXS, site-directed mutagenesis of the recombinant poplar DXS was conducted by alleviating the feedback inhibition from IPP and DMAPP (Banerjee et al. 2016). In addition to DXS, the IDI catalyzes a critical step by converting IPP into its isomer DMAPP, which is important for balancing the available precursors IPP and DMAPP to produce desired terpenoids (Hahn et al. 1999; Yoon et al. 2007). Heterologous overexpression of IDI from Haematococcus pluvialis enabled carotenoid accumulation in E. coli (Sun et al. 1998). Later, the idi gene isolated from Lycium chinense was characterized and overexpressed in E. coli. The $\beta$-carotene of the IDI-overexpressed strain was about twofold higher than of the control strain (Li et al. 2016).

In addition to simple overexpression of rate-limiting enzymes, which may cause metabolic imbalance and suboptimal production of terpenoids, a combinatorial strategy, which included directed co-evolution of key enzymes DXS, DXR and IDI, and promoter modification, was developed to significantly improve isoprene production (Lv et al. 2016). The authors also attributed this success to the establishment of a lycopene-indicated high-throughput screening method. 


\section{Introducing heterologous pathway}

To overcome the limitation and circumvent the natural cryptic regulation of the MEP pathway, introducing the heterologous MVA pathway is a commonly adopted alternative to increase IPP and DMAPP in E. coli (AlonsoGutierrez et al. 2013; Carter et al. 2003; Martin et al. 2003; Vadali et al. 2005; Yoon et al. 2009; Zurbriggen et al. 2012). For example, expression of MVA pathway from Saccharomyces cerevisiae in E. coli increased the production of IPP, DMAPP and the sesquiterpenoid amorphadiene (Martin et al. 2003). On this basis, replacing the HMGR from S. cerevisiae with a more soluble homolog from Staphylococcus aureus (Hedl et al. 2004) resulted in further increase of amorphadiene in E. coli (Newman et al. 2006). Similarly, the MVA pathway from Streptomyces $s p$ was reconstituted in E. coli to produce 11.8fold higher lycopene than that of original E. coli strain (Harada and Misawa 2012). In addition, MVA pathway genes from Streptococcus pneumoniae, Streptococcus pyogenes, S. aureus, Enterococcus faecalis and S. cerevisiae were co-expressed in $E$. coli to achieve a high yield of $\beta$-carotene (Yoon et al. 2009). Introduction of heterologous MVA pathway and optimization of the endogenous MEP pathway resulted in production of $122.4 \mathrm{mg} / \mathrm{L}$ $\beta$-carotene in the engineered $E$. coli strain, which was 113- and 1.7-fold higher than that of strain harboring the native MEP pathway alone and strain harboring the MVA pathway and native MEP pathway, respectively (Yang and Guo 2014). Further, simultaneous or independent overexpression of MEP and MVA pathway was performed in $E$. coli to investigate whether there exists a synergy between the two pathways. According to the ${ }^{13} \mathrm{C}$ labeling result, the MEP pathway flux in strain with overexpression of the dual pathways was 4.8 -fold higher than that of the strain with overexpression of MEP pathway alone, and the MVA pathway flux in the dual pathway overexpressing strain was 1.5-fold greater than that of the strain with overexpression of MVA pathway alone. Finally, the resultant strain harboring dual pathways produced $24 \mathrm{~g} / \mathrm{L}$ isoprene in fed-batch fermentation (Yang et al. 2016).

Compared to the MVA pathway, the MEP pathway is superior in stoichiometry and accumulates less byproduct (Dugar and Stephanopoulos 2011). Researchers tried to reconstitute MEP pathway of E. coli in S. cerevisiae, which only harbors the MVA pathway to produce terpenoid, but failed to get functional expression of 4-hydroxy3-methylbut-2-enyl-diphosphate synthase (IspG) and 4-hydroxy-3-methylbut-2-enyl diphosphate reductase (IspH) (Carlsen et al. 2013; Partow et al. 2012). In the MEP pathway, IspG and IspH are iron-sulfur cluster proteins, which require functional assembly of the [4Fe-4S] iron-sulfur cluster (ISC) (Seemann and Rohmer 2007) and electron transfer by flavodoxin (Fld) and ferredoxin (flavodoxin) $\mathrm{NADP}^{+}$reductase (FNR) (Grawert et al. 2004; Xiao et al. 2009; Zepeck et al. 2005). Co-expression of IspG from Bacillus thuringiensis, IspH from $E$. coli, Fld from Bacillus subtilis, FNR from Arabidopsis and ISC from $E$. coli successfully reconstituted MEP pathway in $S$. cerevisiae (Kirby et al. 2016).

\section{Enhancing the interaction between the MVA and MEP pathway}

As mentioned above, plants naturally harbor the MVA and MEP pathway in cytoplasm and plastid, respectively. Single blocking the MVA or MEP pathway cannot completely block terpenoid biosynthesis in cytoplasm or plastid, indicating that the common precursor of these two pathways (e.g., IPP, GPP, FPP, and GGPP) can be freely transported into different subcellular regions (Aharoni et al. 2004; Asaph et al. 2003; Bick and Lange 2003; Bouvier et al. 2000; Hemmerlin et al. 2003; Kasahara et al. 2002; Laule et al. 2003; Gutensohn et al. 2013). Therefore, enhancing such interaction helps to promote terpenoid biosynthesis (Fig. 3a). In spiked lavender, IPP and DMAPP are mainly produced from the MEP pathway. However, terpenoids 1,8-eucalyptol and camphor increased in the HMGR overexpressed plants (Mendoza-Poudereux et al. 2015). Similarly, overexpression of HMGR in S. miltiorrhiza hairy roots can also enhance the production of diterpenoid tanshinones, which is believed to be produced from the MEP pathway (Kai et al. 2011; Shi et al. 2014). A possible explanation is that more IPP synthesized in the cell cytoplasm is transported into the plastid to serve as the precursor of the MEP pathway. In another study, overexpression of HDR in Artemisia anпиа L. increased the production of artemisinin and other sesquiterpenes. Green florescence protein fusion and confocal microscopy analysis indicated that HDR was localized in the chloroplast, and transport of IPP from chloroplast to cell cytoplasm was observed in the ${ }^{13} \mathrm{C}$ labeling experiment, suggesting that more IPP was available for terpenoid production from the MVA pathway (Ma et al. 2017). In one specific exception, the plastid-localized MEP pathway was the only active pathway for supporting the biosynthesis of plastidial monoterpenoid and cytosolic sesquiterpenoid in snapdragon flowers (Dudareva et al. 2005).

In addition to manipulation of endogenous pathways, exogenous stimuli can also affect the interaction between the MVA and the MEP pathway. One is sugar (Fig. 3b). Sucrose induced the activity of sucrose non-fermenting 1-related protein kinase 1 (SnRK1), which reduced HMGR activity by phosphorylation (Polge and Thomas 2007; Sugden et al. 1999), and accordingly increased substrates for the MEP pathway. As a result, chlorophyll production was increased in 


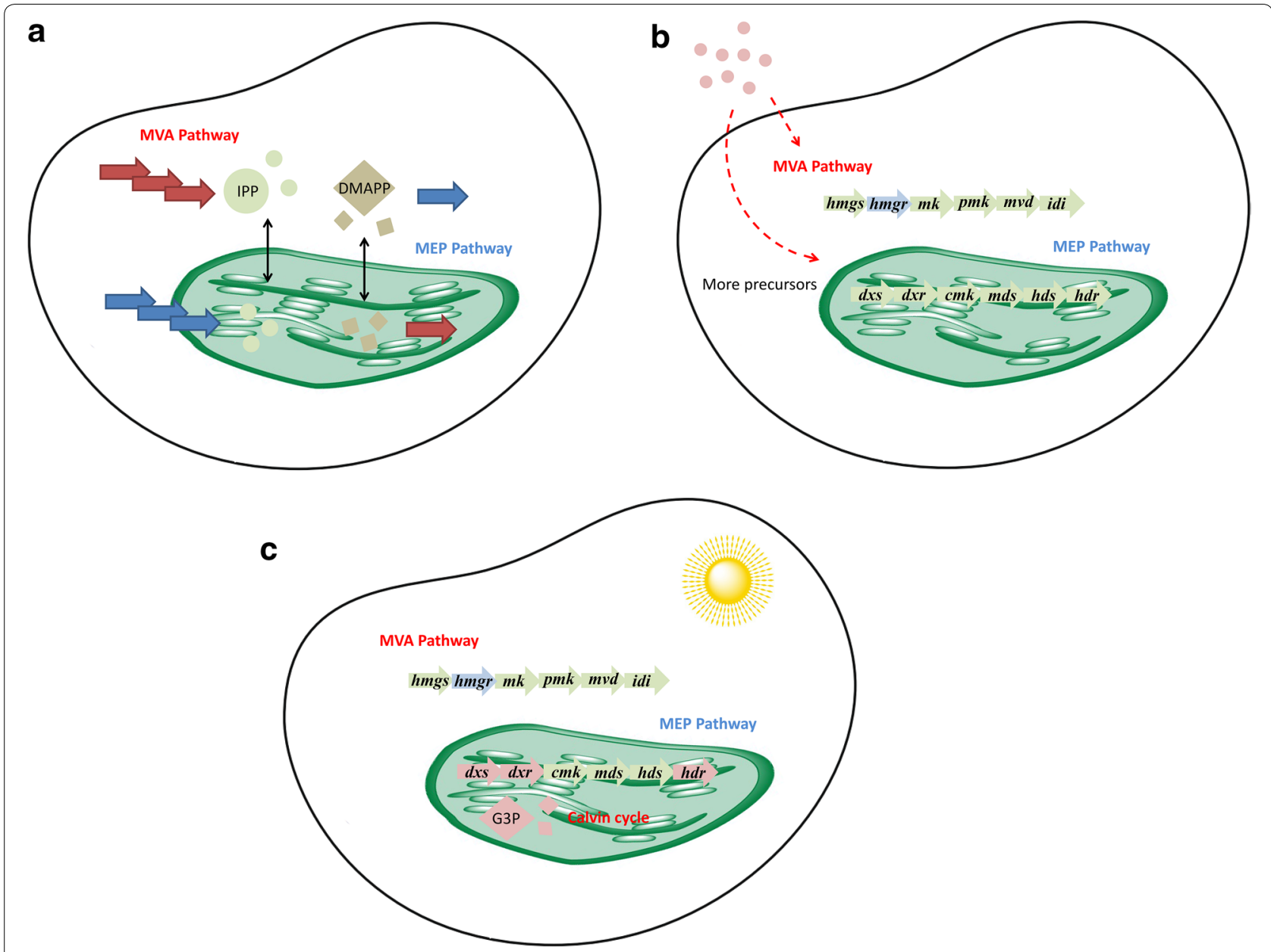

Fig. 3 Enhancing the interaction between the MVA and MEP pathway. a Overexpression of the MVA (MEP) pathway enhances the MEP (MVA) pathway. b Addition of sugar down-regulates the MVA pathway (in blue) and provides sufficient precursors for the MEP pathway. $\mathbf{C}$ Light down-regulates the MVA pathway (in blue) and up-regulates the MEP pathway (in red)

intact Arabidopsis seedlings grown in medium supplemented with sucrose (Laby et al. 2000). Another is light (Fig. 3c). Light down-regulates the expression of MVA pathway genes (Enjuto et al. 1994; Learned 1996; Rodríguez-Concepción 2006; Stermer et al. 1994), but up-regulates the expression of MEP pathway genes, including DXS, DXR and HDR (Botella-Pavia et al. 2004; Carretero-Paulet et al. 2002; Cordoba et al. 2009; Hans et al. 2004; Hsieh and Goodman 2005; Rodríguez-Concepción 2006). In addition, photo-triggered metabolism results in the increased production of substrates (e.g., G3P from the Calvin cycle) for the MEP pathway, which helps to increase IPP and DMAPP production in chloroplasts and leads to an increase in MEP-derived terpenoids.

\section{Attenuation of the toxicity of IPP and DMAPP}

As indicated in many investigations, accumulation of IPP, DMAPP, and other intermediates may affect cell growth and terpenoid biosynthesis in various species (Anthony et al. 2009; Martin et al. 2003; Pitera et al. 2007; Sivy et al. 2011). On one hand, overexpression of the downstream enzyme could effectively attenuate their toxicity. To improve sesquiterpene $\beta$-farnesene production, genes encoding farnesyl diphosphate synthase (isp $A)$ and $\beta$-farnesene synthase $(f g)$ were expressed in E. coli, but the yield of $\beta$-farnesene was very low due to the inhibited cell growth caused by IPP accumulation. To solve 
this problem, overexpression of IDI and IspA successfully reduced the IPP content. The engineered strain produced 800-times higher $\beta$-farnesene than that of the control strain (You et al. 2017). Except for direct overexpression of enzymes, modification of key elements [e.g., promoter, ribosome binding site (RBS), etc.] is also crucial for regulating the enzyme activity. In one study, a series of FPP-responsive promoters were constructed to dynamically regulate ADS expression to maintain FPP at a non-toxic level. The terpenoid production of the engineered strain was doubled as compared to the control strain using a traditional inducible promoter to drive the expression of ADS (Dahl et al. 2013). In another study, different strengths of RBS were selected for improving the translation efficiency of MVA pathway enzymes. As a result, using the medium-strength RBS for translation of MK, PMK, MVD, and ADS reduced the accumulation and excessive consumption of FPP in E. coli, and improving the production of amorphadiene by about fivefold (Nowroozi et al. 2014).

On the other hand, construction of a shunt pathway is also adopted as an alternative to alleviate the toxicity of IPP and DMAPP. To rescue the impaired cell growth caused by the accumulated IPP in E. coli, overexpression of MPD from S. cerevisiae was accordingly performed to dephosphorylate IPP to IP (Kang et al. 2016). Except for MPD, enzymes belong to the nudix hydrolase superfamily can also dephosphorylate IPP and DMAPP (Dunn et al. 1999; Mildvan et al. 2005). The IPP content was significantly reduced after overexpression of $n u d B$ in $E$. coli (George et al. 2014), and growth inhibition was relieved. Further, George et al. optimized the Shine-Dalgarno sequence of $n u d B$ to construct a more efficient NUDB to reduce IPP (George et al. 2015). In a recent study, the effects of IPP accumulation in E. coli were comprehensively assessed, which provided more novel targets for alleviating IPP toxicity (George et al. 2018).

\section{Utilization of the toxicity of IPP and DMAPP to discover or engineer downstream enzymes}

Relying on the reduced cell growth caused by IPP toxicity, attractive methods were developed to discover or engineer downstream enzymes for terpenoid biosynthesis. These toxicity-based screening methods are wide applicable regardless of host cells. In one example, the Bacillus genomic DNA library was introduced into an engineered E. coli strain capable of producing excessive levels of IPP and DMAPP, to screen mutants with restored cell growth and discover potential downstream enzymes for hemiterpenoid production. As a result, two genes $(y h f R$ and $n u d F$ ) were discovered as prenyl phosphatases, which could catalyze IPP and DMAPP to form isopentenol (Withers et al. 2007). In another example, similar method was adopted for directed evolution of isoprene synthase (ISPS) with enhanced catalytic activity on DMAPP. Combined with protein engineering and metabolic engineering strategies, the engineered S. cerevisiae strain was able to produce $3.7 \mathrm{~g} / \mathrm{L}$ isoprene (Wang et al. 2017).

\section{Conclusions}

Providing a suitable supply of IPP and DMAPP is crucial for efficient terpenoid biosynthesis. Most efforts in manipulating IPP and DMAPP supply focused on rewiring the central metabolic pathway, overcoming the rate-limiting step, introducing heterologous pathway, enhancing the interaction between different pathways, toxicity attenuation and utilization of the toxicity to discover or engineer downstream enzymes, which greatly improved bioproduction of corresponding terpenoids. For all organisms that contain a native pathway to produce terpenoid, strategies including rewiring central metabolic pathway, overcoming the rate-limiting step and toxicity attenuation have excellent potential to generalize. To overcome the natural regulation from the host, introducing heterologous pathway is the method of choice, while enhancing the interaction may harness the advantages of different pathways to support terpenoid biosynthesis. The impaired cell growth caused by the toxicity of IPP and DMAPP allows establishment of a cell growth-based high-throughput screening method to optimize the downstream pathway for higher terpenoid bioproduction. Since addition of exogenous stimuli could regulate the biosynthetic pathways of IPP and DMAPP, and significantly change the terpenoids production profile, it could be more meaningful to construct a combination pathway to produce different terpenoids by exploration of the exogenous stimuli for industrial production. In the future, with the aid of multi-level omics studies (Alcalde and Fraser 2018; Martinez-Esteso et al. 2015; Vickery et al. 2016) and various genome editing tools (e.g., CRISPR-Cas9), multiple metabolic engineering endeavors can be performed in parallel to test potential combinatorial effects of above-mentioned strategies in a highly efficient manner. In addition to targeting pathway genes, fine-tuning host regulation also plays vital role for supplying IPP and DMAPP (Fitzpatrick et al. 2011; Hemmerlin et al. 2004, 2012; Leivar et al. 2011), which could be considered as a promising alternative for further improving terpenoid biosynthesis.

\footnotetext{
Abbreviations

IPP: isopentenyl diphosphate; DMAPP: dimethylallyl diphosphate; GPP: geranyl diphosphate; FPP: farnesyl diphosphate; GGPP: geranylgeranyl diphosphate; MVA: mevalonate; MEP: 2-C-methyl-D-erythritol 4-phosphate; AACT: acetylCoA acetyltransferase; HMGS: hydroxymethylglutaryl-CoA synthase; HMG-CoA: 3-hydroxy-3-methylglutaryl-CoA; HMGR: 3-hydroxy-3-methylglutaryl-CoA reductase; MK: mevalonate kinase; PMK: phosphomevalonate kinase; MVD:
} 
diphosphomevalonate decarboxylase; IDI: isopentenyl diphosphate isomerase; IPK: isopentenyl phosphate kinase; IP: isopentenyl phosphate; MPD: phosphomevalonate decarboxylase; MVP: 5-phosphomevalonate; G3P: glyceraldehyde 3-phosphate; DXS: 1-deoxy-D-xylulose-5-phosphate synthase; DXP: 1-deoxy-D-xylulose 5-phosphate; MCT: 2-C-methyl-D-erythritol 4-phosphate cytidylyltransferase; CD-ME: 4-(cytidine 5'-diphospho)-2-C-methyl-D-erythritol; HMBPP: 1-hydroxy-2-methyl-2-butenyl-4-diphosphate; CMK: 4-diphosphocytidyl-2-C-methyl-D-erythritol kinase; MDS: 2-C-methyl-D-erythritol 2,4-cyclodiphosphate synthase; HDS: 4-hydroxy-3-methylbut-2-enyl-diphosphate synthase; HDR: 4-hydroxy-3-methylbut-2-enyl diphosphate reductase; MTA: 5-methylthioadenosine; MtnP: MTA phosphorylase; MTR-1 P: 5-methylthioD-ribose-1-phosphate; MTRu-1P: 5-methylthio-D-ribulose-1-phosphate; MtnA: MTR-1P isomerase; MTRu-5P: 1-methylthio-ribulose-5-phosphate; MTXu-5P: 1-methylthio-xylulose-5-phosphate; RLP: ribulose-1,5-bisphosphate carboxylase/oxygenase (RubisCO)-like protein; MVPP: 5-diphosphomevalonate; CD-ME2P: 2-phospho-4-(cytidine 5'-diphospho)-2-C-methyl-D-erythritol; ME-cPP: 2-C-methyl-D-erythritol 2,4-cyclodiphosphate; Phos: phosphatase(s); DXR: 1-deoxy-D-xylulose-5-phosphate reductoisomerase; Cupin: 1-methylthioxylulose-5-phosphate methylsufurylase; GPS: GPP synthase; FPS: FPP synthase; GGPS: GGPP synthase; PEP: phosphoenolpyruvate; PGM: phosphoglycerate mutase; ENO: enolase; PK: pyruvate kinase; PCK: PEP carboxykinase; PPS: PEP synthase; EMP: Embden-Meyerhof pathway; EDP: Entner-Doudoroff pathway; PPP: pentose phosphate pathway; Glu: glucose; Pyr: pyruvate; A: acetyl-CoA; OAA: oxaloacetate; t-HMGR: truncated HMGR; DMAP: 4-dimethylaminopyridine; IspG: 4-hydroxy-3-methylbut-2-enyl-diphosphate synthase; IspH: 4-hydroxy-3-methylbut-2-enyl diphosphate reductase; ISC: [4Fe-4S] iron-sulfur cluster; FNR: ferredoxin (flavodoxin) NADP ${ }^{+}$reductase; SnRK1: sucrose nonfermenting 1-related protein kinase 1; IspA: farnesyl diphosphate synthase; Fg: $\beta$-farnesene synthase; RBS: ribosome binding site; ISPS: isoprene synthase.

\section{Authors' contributions}

HX conceived the study. QW collected references and prepared the draft with assistance from SQ. HX finalized the manuscript. All authors read and approved the final manuscript.

\section{Author details}

${ }^{1}$ State Key Laboratory of Microbial Metabolism, Joint International Research Laboratory of Metabolic \& Developmental Sciences, and Laboratory of Molecular Biochemical Engineering, School of Life Sciences and Biotechnology, Shanghai Jiao Tong University, 800 Dong-chuan Road, Shanghai 200240, China. ${ }^{2}$ State Key Laboratory of Bioreactor Engineering, East China University of Science and Technology, Shanghai Collaborative Innovation Center for Biomanufacturing (SCICB), Shanghai 200237, China.

\section{Acknowledgements}

H.X. gratefully acknowledges all the financial support.

\section{Competing interests}

The authors declare that they have no competing interests.

\section{Availability of data and materials}

Not applicable.

\section{Consent for publication}

Not applicable.

\section{Ethics approval and consent to participate} Not applicable.

\section{Funding}

This work was supported by the National Natural Science Foundation of China (No. 31600071), Municipal Natural Science Foundation of Shanghai (Nos. 17ZR1448900, 18ZR1420300), and Open Funding Project of the State Key Laboratory of Bioreactor Engineering.

\section{Publisher's Note}

Springer Nature remains neutral with regard to jurisdictional claims in published maps and institutional affiliations.
Received: 27 November 2018 Accepted: 31 January 2019

Published online: 06 February 2019

\section{References}

Aharoni A, Giri AP, Verstappen FW, Bertea CM, Sevenier R, Sun Z, Jongsma MA, Schwab W, Bouwmeester HJ (2004) Gain and loss of fruit flavor compounds produced by wild and cultivated strawberry species. Plant Cell 16(11):3110-3131

Ajikumar PK, Tyo K, Carlsen S, Mucha O, Phon TH, Stephanopoulos G (2008) Terpenoids: opportunities for biosynthesis of natural product drugs using engineered microorganisms. Mol Pharm 5(2):167-190

Alcalde E, Fraser PD (2018) Extending our tools and resources in the nonconventional industrial yeast Xanthophyllomyces dendrorhous through the application of metabolite profiling methodologies. Metabolomics 14(3):30

Alonso-Gutierrez J, Chan R, Batth TS, Adams PD, Keasling JD, Petzold CJ, Lee TS (2013) Metabolic engineering of Escherichia coli for limonene and perillyl alcohol production. Metab Eng 19:33-41

Anthony JR, Anthony LC, Nowroozi F, Kwon G, Newman JD, Keasling JD (2009) Optimization of the mevalonate-based isoprenoid biosynthetic pathway in Escherichia coli for production of the anti-malarial drug precursor amorpha-4,11-diene. Metab Eng 11(1):13-19

Asaph A, Giri AP, Stephan D, Frans G, Willem-Jan DK, Verstappen FWA, Verhoeven HA, Jongsma MA, Wilfried S, Bouwmeester HJ (2003) Terpenoid metabolism in wild-type and transgenic Arabidopsis plants. Plant Cell 15(12):2866

Bach TJ (1986) Hydroxymethylglutaryl-CoA reductase, a key enzyme in phytosterol synthesis? Lipids 21(1):82-88

Bach TJ, Lichtenthaler HK (2010) Inhibition by mevinolin of plant growth, sterol formation and pigment accumulation. Physiol Plant 59(1):50-60

Banerjee A, Preiser AL, Sharkey TD (2016) Engineering of recombinant poplar deoxy-D-xylulose-5-phosphate synthase (PtDXS) by site-directed mutagenesis improves its activity. PLoS ONE 11(8):e0161534

Bian G, Deng Z, Liu T (2017) Strategies for terpenoid overproduction and new terpenoid discovery. Curr Opin Biotechnol 48:234-241

Bick JA, Lange BM (2003) Metabolic cross talk between cytosolic and plastidial pathways of isoprenoid biosynthesis: unidirectional transport of intermediates across the chloroplast envelope membrane. Arch Biochem Biophys 415(2): 146-154

Bochar DA, Friesen JA, Stauffacher CV, Rodwell VW (1999) Biosynthesis of mevalonic acid from acetyl-CoA. In: Barton SD, Nakanishi K, Meth-Cohn $\mathrm{O}$ (eds) Comprehensive natural products chemistry. Elsevier, London

Boiteux A, Markus M, Plesser T, Hess B, Malcovati M (1983) Analysis of progress curves. Interaction of pyruvate kinase from Escherichia coli with fructose 1,6-bisphosphate and calcium ions. Biochem J 211(3):631-640

Botella-Pavia P, Besumbes O, Phillips MA, Carretero-Paulet L, Boronat A, Rodriguez-Concepcion M (2004) Regulation of carotenoid biosynthesis in plants: evidence for a key role of hydroxymethylbutenyl diphosphate reductase in controlling the supply of plastidial isoprenoid precursors. Plant J 40(2):188-199

Boucher Y, Doolittle WF (2000) The role of lateral gene transfer in the evolution of isoprenoid biosynthesis pathways. Mol Microbiol 37(4):703-716

Bouvier F, Suire C, d'Harlingue A, Backhaus RA, Camara B (2000) Molecular cloning of geranyl diphosphate synthase and compartmentation of monoterpene synthesis in plant cells. Plant J 24(2):241-252

Braithwaite GD, Goodwin TW (1960a) Studies in carotenogenesis. 25. The incorporation of $\left[1-{ }^{14} \mathrm{C}\right]$ acetate, $\left[2-{ }^{-14} \mathrm{C}\right]$ acetate and ${ }^{14} \mathrm{CO}_{2}$ into lycopene by tomato slices. Biochem J 76:1-5

Braithwaite GD, Goodwin TW (1960b) Studies in carotenogenesis. 27 Incorporation of $\left[2-{ }^{14} \mathrm{C}\right]$ acetate, $\mathrm{DL}-\left[2-{ }^{14} \mathrm{C}\right]$ mevalonate and ${ }^{14} \mathrm{CO}_{2}$ into carrotroot preparations. Biochem J 76:194-197

Carlsen S, Ajikumar PK, Formenti LR, Zhou K, Phon TH, Nielsen ML, Lantz AE, Kielland-Brandt MC, Stephanopoulos G (2013) Heterologous expression and characterization of bacterial 2-C-methyl-D-erythritol 4-phosphate pathway in Saccharomyces cerevisiae. Appl Microbiol Biotechnol 97(13):5753-5769

Carretero-Paulet L, Ahumada I, Cunillera N, Rodriguez-Concepcion M, Ferrer A, Boronat A, Campos N (2002) Expression and molecular analysis of the Arabidopsis DXR gene encoding 1-deoxy-D-xylulose 5-phosphate 
reductoisomerase, the first committed enzyme of the 2-C-methylD-erythritol 4-phosphate pathway. Plant Physiol 129(4):1581-1591

Carter OA, Peters RJ, Croteau R (2003) Monoterpene biosynthesis pathway construction in Escherichia coli. Phytochemistry 64(2):425-433

Chappell J, Wolf F, Proulx J, Cuellar R, Saunders C (1995) Is the reaction catalyzed by 3-hydroxy-3-methylglutaryl coenzyme A reductase a rate-limiting step for isoprenoid biosynthesis in plants? Plant Physiol 109(4):1337-1343

Chun KT, Bar-Nun S, Simoni RD (1990) The regulated degradation of 3-hydroxy-3-methylglutaryl-CoA reductase requires a short-lived protein and occurs in the endoplasmic reticulum. J Biol Chem 265(35):22004-22010

Clark DP (1989) The fermentation pathways of Escherichia coli. FEMS Microbiol Rev 5(3):223-234

Connolly JD, Hill RA (1991) Dictionary of terpenoids. Chapman and Hall, London

Cordoba E, Salmi M, Leon P (2009) Unravelling the regulatory mechanisms that modulate the MEP pathway in higher plants. J Exp Bot 60(10):2933-2943

Dahl RH, Zhang F, Alonso-Gutierrez J, Baidoo E, Batth TS, Redding-Johanson AM, Petzold CJ, Mukhopadhyay A, Lee TS, Adams PD, Keasling JD (2013) Engineering dynamic pathway regulation using stress-response promoters. Nat Biotechnol 31(11):1039-1046

Dellas N, Thomas ST, Manning G, Noel JP (2013) Discovery of a metabolic alternative to the classical mevalonate pathway. Elife 2:e00672

Dudareva N, Andersson S, Orlova I, Gatto N, Reichelt M, Rhodes D, Boland W, Gershenzon J (2005) The nonmevalonate pathway supports both monoterpene and sesquiterpene formation in snapdragon flowers. Proc Natl Acad Sci USA 102(3):933-938

Dugar D, Stephanopoulos G (2011) Relative potential of biosynthetic pathways for biofuels and bio-based products. Nat Biotechnol 29(12):1074-1078

Dunn CA, O'Handley SF, Frick DN, Bessman MJ (1999) Studies on the ADPribose pyrophosphatase subfamily of the nudix hydrolases and tentative identification of $\operatorname{trg} B$, a gene associated with tellurite resistance. J Biol Chem 274(45):32318-32324

Enfissi EM, Fraser PD, Lois LM, Boronat A, Schuch W, Bramley PM (2005) Metabolic engineering of the mevalonate and non-mevalonate isopentenyl diphosphate-forming pathways for the production of health-promoting isoprenoids in tomato. Plant Biotechnol J 3(1):17-27

Enjuto M, Balcells L, Campos N, Caelles C, Arro M, Boronat A (1994) Arabidopsis thaliana contains two differentially expressed 3-hydroxy-3-methylglutaryl-CoA reductase genes, which encode microsomal forms of the enzyme. Proc Natl Acad Sci USA 91(3):927-931

Erb TJ, Evans BS, Cho K, Warlick BP, Sriram J, Wood MK, Imker HJ, Sweedler JV, Tabita FR, Gerlt JA, Erb T et al (2012) A RubisCO-like protein links SAM metabolism with isoprenoid biosynthesis. Nat Chem Biol 8(11):926-932

Estevez JM, Cantero A, Reindl A, Reichler S, Leon P (2001) 1-Deoxy-D-xylulose5-phosphate synthase, a limiting enzyme for plastidic isoprenoid biosynthesis in plants. J Biol Chem 276(25):22901-22909

Farmer WR, Liao JC (2001) Precursor balancing for metabolic engineering of lycopene production in Escherichia coli. Biotechnol Prog 17(1):57-61

Felix R, Stefan H, Katrin GR, Petra A, Cornelia K, Sabine A, Duilio A, Adelbert B, Wolfgang $E$ (2002) Studies on the nonmevalonate terpene biosynthetic pathway: metabolic role of IspH (LytB) protein. Proc Natl Acad Sci USA 99(3):1158-1163

Fitzpatrick AH, Bhandari J, Crowell DN (2011) Farnesol kinase is involved in farnesol metabolism, ABA signaling and flower development in Arabidopsis. Plant J 66(6):1078-1088

Formighieri C, Melis A (2014) Carbon partitioning to the terpenoid biosynthetic pathway enables heterologous $\beta$-phellandrene production in Escherichia coli cultures. Arch Microbiol 196(12):853-861

Geerse RH, van der Pluijm J, Postma PW (1989) The repressor of the PEP: fructose phosphotransferase system is required for the transcription of the pps gene of Escherichia coli. Mol Gen Genet 218(2):348-352

George KW, Chen A, Jain A, Batth TS, Baidoo EE, Wang G, Adams PD, Petzold CJ, Keasling JD, Lee TS (2014) Correlation analysis of targeted proteins and metabolites to assess and engineer microbial isopentenol production. Biotechnol Bioeng 111(8):1648-1658

George KW, Thompson MG, Kang A, Baidoo E, Wang G, Chan L, Adams PD, Petzold CJ, Keasling JD, Lee TS (2015) Metabolic engineering for the high-yield production of isoprenoid-based C(5) alcohols in E. coli. Sci Rep 5:11128

George KW, Thompson MG, Kim J, Baidoo EEK, Wang G, Benites VT, Petzold CJ, Chan LG, Yilmaz S, Turhanen P, Adams PD, Keasling JD, Lee TS (2018) Integrated analysis of isopentenyl pyrophosphate (IPP) toxicity in isoprenoid-producing Escherichia coli. Metab Eng 47:60-72

Goldstein JL, Brown MS (1990) Regulation of the mevalonate pathway. Nature 343(6257):425-430

Goodwin TW (1958) Studies in carotenogenesis. 25. The incorporation of ${ }^{14} \mathrm{CO}_{2},\left[2-{ }^{14} \mathrm{C}\right]$ acetate and $\left[2-{ }^{14} \mathrm{C}\right]$ mevalonate into $\beta$-carotene by illuminated etiolated maize seedings. Biochem J 70(4):612-617

Grawert T, Kaiser J, Zepeck F, Laupitz R, Hecht S, Amslinger S, Schramek N, Schleicher E, Weber S, Haslbeck M, Buchner J, Rieder C, Arigoni D, Bacher A, Eisenreich W, Rohdich F (2004) IspH protein of Escherichia coli: studies on iron-sulfur cluster implementation and catalysis. J Am Chem Soc 126(40):12847-12855

Grochowski LL, Xu H, White RH (2006) Methanocaldococcus jannaschii uses a modified mevalonate pathway for biosynthesis of isopentenyl diphosphate. J Bacteriol 188(9):3192-3198

Gutensohn M, Orlova I, Nguyen TT, Davidovich-Rikanati R, Ferruzzi MG, Sitrit Y, Lewinsohn E, Pichersky E, Dudareva N (2013) Cytosolic monoterpene biosynthesis is supported by plastid-generated geranyl diphosphate substrate in transgenic tomato fruits. Plant J 75(3):351-363

Hahn FM, Hurlburt AP, Poulter CD (1999) Escherichia coli open reading frame 696 is idi, a nonessential gene encoding isopentenyl diphosphate isomerase. J Bacteriol 181(15):4499-4504

Hampton RY, Rine J (1994) Regulated degradation of HMG-CoA reductase, an integral membrane protein of the endoplasmic reticulum, in yeast. J Cell Biol 125(2):299-312

Hans J, Hause B, Strack D, Walter MH (2004) Cloning, characterization, and immunolocalization of a mycorrhiza-inducible 1-deoxy-D-xylulose 5-phosphate reductoisomerase in arbuscule-containing cells of maize. Plant Physiol 134(2):614-624

Harada H, Misawa N (2012) Novel approach in the biosynthesis of functional carotenoids in Escherichia coli. Methods Mol Biol 892(1):33-141

Hedl M, Tabernero L, Stauffacher CV, Rodwell VW (2004) Class II 3-hydroxy3-methylglutaryl coenzyme A reductases. J Bacteriol 186(7):1927-1932

Hemmerlin A, Hoeffler JF, Meyer O, Tritsch D, Kagan IA, GrosdemangeBilliard C, Rohmer M, Bach TJ (2003) Cross-talk between the cytosolic mevalonate and the plastidial methylerythritol phosphate pathways in tobacco bright yellow-2 cells. J Biol Chem 278(29):26666-26676

Hemmerlin A, Gerber E, Feldtrauer JF, Wentzinger L, Hartmann MA, Tritsch D, Hoeffler JF, Rohmer M, Bach TJ (2004) A review of tobacco BY-2 cells as an excellent system to study the synthesis and function of sterols and other isoprenoids. Lipids 39(8):723-735

Hemmerlin A, Harwood JL, Bach TJ (2012) A raison d'etre for two distinct pathways in the early steps of plant isoprenoid biosynthesis? Prog Lipid Res 51(2):95-148

Henry LK, Gutensohn M, Thomas ST, Noel JP, Dudareva N (2015) Orthologs of the archaeal isopentenyl phosphate kinase regulate terpenoid production in plants. Proc Natl Acad Sci USA 112(32):10050-10055

Henry LK, Thomas ST, Widhalm JR, Lynch JH, Davis TC, Kessler SA, Bohlmann J, Noel JP, Dudareva N (2018) Contribution of isopentenyl phosphate to plant terpenoid metabolism. Nat Plants 4(9):721-729

Herz S, Wungsintaweekul J, Schuhr CA, Hecht S, Luttgen H, Sagner S, Fellermeier M, Eisenreich W, Zenk MH, Bacher A, Rohdich F (2000) Biosynthesis of terpenoids: YgbB protein converts 4-diphosphocytidyl-2C-methyl-D-erythritol 2-phosphate to 2C-methyl-D-erythritol 2,4-cyclodiphosphate. Proc Natl Acad Sci USA 97(6):2486-2490

Holmberg N, Harker M, Wallace AD, Clayton JC, Gibbard CL, Safford R (2003) Co-expression of $\mathrm{N}$-terminal truncated 3-hydroxy-3-methylglutaryl CoA reductase and C24-sterol methyltransferase type 1 in transgenic tobacco enhances carbon flux towards end-product sterols. Plant J 36(1):12-20

Hsieh MH, Goodman HM (2005) The Arabidopsis IspH homolog is involved in the plastid nonmevalonate pathway of isoprenoid biosynthesis. Plant Physiol 138(2):641-653

Ignea C, Cvetkvoic I, Loupassaki S, Kefalas P, Johnson CB, Kampranis SC, Makris AM (2011) Improving yeast strains using recyclable integration cassettes, for the prodction of plant terpenoids. Microb Cell Fact 10:4 
Imker HJ, Singh J, Warlick BP, Tabita FR, Gerlt JA (2008) Mechanistic diversity in the RubisCO superfamily: a novel isomerization reaction catalyzed by the RuBisCO-Like protein from Rhodospirillum rubrum. Biochemistry 47(43): 11171

Immethun CM, Hoynes-O'Connor AG, Balassy A, Moon TS (2013) Microbial production of isoprenoids enabled by synthetic biology. Front Microbiol 4:75

Kai G, Xu H, Zhou C, Liao P, Xiao J, Luo X, You L, Zhang L (2011) Metabolic engineering tanshinone biosynthetic pathway in Salvia miltiorrhiza hairy root cultures. Metab Eng 13(3):319-327

Kaneda K, Kuzuyama T, Takagi M, Hayakawa Y, Seto H (2001) An unusual isopentenyl diphosphate isomerase found in the mevalonate pathway gene cluster from Streptomyces sp. strain CL190. Proc Natl Acad Sci USA 98(3):932-937

Kang A, George KW, Wang G, Baidoo E, Keasling JD, Lee TS (2016) Isopentenyl diphosphate (IPP)-bypass mevalonate pathways for isopentenol production. Metab Eng 34:25-35

Karine B, Yannick E, Alain D, Frédéric P (2012) Isopentenyl diphosphate isomerase: a checkpoint to isoprenoid biosynthesis. Biochimie 94(8):1621-1634

Kasahara H, Hanada A, Kuzuyama T, Takagi M, Kamiya Y, Yamaguchi S (2002) Contribution of the mevalonate and methylerythritol phosphate pathways to the biosynthesis of gibberellins in Arabidopsis. J Biol Chem 277(47):45188-45194

Kim SJ, Kim MD, Choi JH, Kim SY, Ryu YW, Seo JH (2006) Amplification of 1-deoxy-D-xyluose 5-phosphate (DXP) synthase level increases coenzyme Q10 production in recombinant Escherichia coli. Appl Microbiol Biotechnol 72(5):982-985

Kim YK, Kim JK, Kim YB, Lee S, Kim SU, Park SU (2013) Enhanced accumulation of phytosterol and triterpene in hairy root cultures of Platycodon grandiflorum by overexpression of Panax ginseng 3-hydroxy-3-methylglutarylcoenzyme A reductase. J Agric Food Chem 61(8):1928-1934

Kirby J, Dietzel KL, Wichmann G, Chan R, Antipov E, Moss N, Baidoo EEK, Jackson P, Gaucher SP, Gottlieb S, LaBarge J, Mahatdejkul T, Hawkins KM, Muley S, Newman JD, Liu P, Keasling JD, Zhao L (2016) Engineering a functional 1-deoxy-D-xylulose 5-phosphate (DXP) pathway in Saccharomyces cerevisiae. Metab Eng 38:494-503

Kuzuyama TTS, Watanabe H, Seto H (1998) Direct formation of 2-C-methylD-erythritol 4-phosphate from 1-deoxy-D-xylulose 5-phosphate by 1-deoxy-D-xylulose 5-phosphate reductisomerase, a new enzyme in the non-mevalonate pathway to isopentenyl diphosphate. Tetrahedron Lett 39(25):4509-4512

Kuzuyama T, Takagi M, Takahashi S, Seto H (2000) Cloning and characterization of 1-deoxy-D-xylulose 5-phosphate synthase from Streptomyces sp. strain CL190, which uses both the mevalonate and nonmevaIonate pathways for isopentenyl diphosphate biosynthesis. J Bacteriol 182(4):891-897

Laby RJ, Kincaid MS, Kim D, Gibson SI (2000) The Arabidopsis sugar-insensitive mutants sis 4 and sis 5 are defective in abscisic acid synthesis and response. Plant J 23(5):587-596

Lange BM, Rujan T, Martin W, Croteau R (2000) Isoprenoid biosynthesis: the evolution of two ancient and distinct pathways across genomes. Proc Natl Acad Sci USA 97(24):13172-13177

Laskovics FM, Poulter CD (1981) Prenyltransferase; determination of the binding mechanism and individual kinetic constants for farnesylpyrophosphate synthetase by rapid quench and isotope partitioning experiments. Biochemistry 20(7):1893-1901

Laule O, Furholz A, Chang HS, Zhu T, Wang X, Heifetz PB, Gruissem W, Lange M (2003) Crosstalk between cytosolic and plastidial pathways of isoprenoid biosynthesis in Arabidopsis thaliana. Proc Natl Acad Sci USA 100(11):6866-6871

Learned RM (1996) Light suppresses 3-Hydroxy-3-methylglutaryl coenzyme A reductase gene expression in Arabidopsis thaliana. Plant Physiol 110(2):645-655

Leivar P, Antolin-Llovera M, Ferrero S, Closa M, Arro M, Ferrer A, Boronat A, Campos N (2011) Multilevel control of Arabidopsis 3-hydroxy-3-methylglutaryl coenzyme A reductase by protein phosphatase 2A. Plant Cell 23(4):1494-1511

Leonard E, Ajikumar PK, Thayer K, Xiao WH, Mo JD, Tidor B, Stephanopoulos $\mathrm{G}$, Prather KL (2010) Combining metabolic and protein engineering of a terpenoid biosynthetic pathway for overproduction and selectivity control. Proc Natl Acad Sci USA 107(31):13654-13659

Li Z, Ji J, Wang G, Josine TL, Wu J, Diao J, Wu W, Guan C (2016) Cloning and heterologous expression of isopentenyl diphosphate isomerase gene from Lycium chinense. J Plant Biochem Biotechnol 25(1):40-48

Liao P, Wang H, Hemmerlin A, Nagegowda DA, Bach TJ, Wang M, Chye ML (2014) Past achievements, current status and future perspectives of studies on 3-hydroxy-3-methylglutaryl-CoA synthase (HMGS) in the mevalonate (MVA) pathway. Plant Cell Rep 33(7):1005-1022

Liao P, Hemmerlin A, Bach TJ, Chye ML (2016) The potential of the mevaIonate pathway for enhanced isoprenoid production. Biotechnol Adv 34(5):697-713

Liao P, Chen X, Wang M, Bach TJ, Chye ML (2018) Improved fruit alpha-tocopherol, carotenoid, squalene and phytosterol contents through manipulation of Brassica juncea 3-hydroxy-3-methylglutaryl-CoA synthase 1 in transgenic tomato. Plant Biotechnol J 16(3):784-796

Lichtenthaler HK (1999) The 1-deoxy-D-xylulose-5-phosphate pathway of isoprenoid biosynthesis in plants. Annu Rev Plant Physiol Plant Mol Biol 50(50):47-65

Lichtenthaler HK, Bach TJ, Wellburn AR (1982) Cytoplasmic and plastidic isoprenoid compounds of oat seedlings and their distinct labeling from ${ }^{14} \mathrm{C}$-mevalonate. In: Wintermans JFGM, Kuiper P (eds) Biochemistry and metabolism of plant lipids. Elsevier, Amsterdam

Lichtenthaler HK, Rohmer M, Schwender J (1997) Two independent biochemical pathways for isopentenyl diphosphate and isoprenoid biosynthesis in higher plants. Physiol Plant 101(3):643-652

Little HN, Bloch K (1950) Studies on the utilization of acetic acid for the biological synthesis of cholesterol. J Biol Chem 183(1):33-46

Liu H, Sun Y, Ramos KRM, Nisola GM, Valdehuesa KNG, Lee WK, Park SJ, Chung WJ (2013) Combination of Entner-Doudoroff pathway with MEP increases isoprene production in engineered Escherichia coli. PLOS ONE 8(12):e83290

Luthra R, Luthra PM, Kumar S (1999) Redefined role of mevalonate-isoprenoid pathway in terpenoid biosynthesis in higher plants. Curr Sci 76(2):133-135

Lutke-Brinkhaus F, Kleinig H (1987) Formation of isopentenyl diphosphate via mevalonate does not occur within etioplasts and etiochloroplasts of mustard (Sinapis alba L.) seedlings. Planta 171(3):406-411

Lv X, Gu J, Wang F, Xie W, Liu M, Ye L, Yu H (2016) Combinatorial pathway optimization in Escherichia coli by directed co-evolution of rate-limiting enzymes and modular pathway engineering. Biotechnol Bioeng 113(12):2661-2669

Ma SM, Garcia DE, Redding-Johanson AM, Friedland GD, Chan R, Batth TS, Haliburton JR, Chivian D, Keasling JD, Petzold CJ, Lee TS, Chhabra SR (2011) Optimization of a heterologous mevalonate pathway through the use of variant HMG-CoA reductases. Metab Eng 13(5):588-597

Ma D, Li G, Zhu Y, Xie DY (2017) Overexpression and suppression of Artemisia annua 4-hydroxy-3-methylbut-2-enyl diphosphate reductase 1 gene (AaHDR1) differentially regulate artemisinin and terpenoid biosynthesis. Front Plant Sci 8:77

Martin VJ, Pitera DJ, Withers ST, Newman JD, Keasling JD (2003) Engineering a mevalonate pathway in Escherichia coli for production of terpenoids. Nat Biotechnol 21(7):796-802

Martinez-Esteso MJ, Martinez-Marquez A, Selles-Marchart S, Morante-Carriel JA, Bru-Martinez R (2015) The role of proteomics in progressing insights into plant secondary metabolism. Front Plant Sci 6:504

Mcgarvey DJ, Croteau R (1995) Terpenoid metabolism. Plant Cell 7(7):1015-1026

Mendoza-Poudereux I, Kutzner E, Huber C, Segura J, Eisenreich W, Arrillaga I (2015) Metabolic cross-talk between pathways of terpenoid backbone biosynthesis in spike lavender. Plant Physiol Biochem 95:113-120

Mildvan AS, Xia Z, Azurmendi HF, Saraswat V, Legler PM, Massiah MA, Gabelli SB, Bianchet MA, Kang LW, Amzel LM (2005) Structures and mechanisms of Nudix hydrolases. Arch Biochem Biophys 433(1):129-143

Miller AR, North JA, Wildenthal JA, Tabita FR (2018) Two distinct aerobic methionine salvage pathways generate volatile methanethiol in Rhodopseudomonas palustris. Mbio 9(2):e00407-00418

Munoz-Bertomeu J, Sales E, Ros R, Arrillaga I, Segura J (2007) Up-regulation of an $\mathrm{N}$-terminal truncated 3-hydroxy-3-methylglutaryl CoA reductase enhances production of essential oils and sterols in transgenic Lavandula latifolia. Plant Biotechnol J 5(6):746-758 
Nagegowda DA, Bach TJ, Chye ML (2004) Brassica juncea 3-hydroxy-3-methylglutaryl (HMG)-CoA synthase 1: expression and characterization of recombinant wild-type and mutant enzymes. Biochem J 383(Pt. 3):517-527

Newman JD, Marshall J, Chang M, Nowroozi F, Paradise E, Pitera D, Newman KL, Keasling JD (2006) High-level production of amorpha-4,11-diene in a two-phase partitioning bioreactor of metabolically engineered Escherichia coli. Biotechnol Bioeng 95(4):684-691

Nishimura H, Azami Y, Miyagawa M, Hashimoto C, Yoshimura T, Hemmi H (2013) Biochemical evidence supporting the presence of the classical mevalonate pathway in the thermoacidophilic archaeon Sulfolobus solfataricus. J Biochem 153(5):415-420

Nowroozi FF, Baidoo EE, Ermakov S, Redding-Johanson AM, Batth TS, Petzold CJ, Keasling JD (2014) Metabolic pathway optimization using ribosome binding site variants and combinatorial gene assembly. Appl Microbiol Biotechnol 98(4):1567-1581

Partow S, Siewers V, Daviet L, Schalk M, Nielsen J (2012) Reconstruction and evaluation of the synthetic bacterial MEP pathway in Saccharomyces cerevisiae. PLOS ONE 7(12):e52498

Piironen V, Lindsay DG, Miettinen TA, Toivo J, Lampi AM, Lindsay D, Clifford M (2000) Plant sterols: biosynthesis, biological function and their importance to human nutrition. J Sci Food Agric 80(7):939-966

Pitera DJ, Paddon CJ, Newman JD, Keasling JD (2007) Balancing a heterologous mevalonate pathway for improved isoprenoid production in Escherichia coli. Metab Eng 9(2):193-207

Polge C, Thomas M (2007) SNF1/AMPK/SnRK1 kinases, global regulators at the heart of energy control? Trends Plant Sci 12(1):20-28

Pronk JT, Yde Steensma H, Van Dijken JP (1996) Pyruvate metabolism in Saccharomyces cerevisiae. Yeast 12(16):1607-1633

Ramseier TM, Negre D, Cortay JC, Scarabel M, Cozzone AJ, Saier MH Jr (1993) In vitro binding of the pleiotropic transcriptional regulatory protein, FruR, to the fru, pps, ace, pts and icd operons of Escherichia coli and Salmonella typhimurium. J Mol Biol 234(1):28-44

Ro DK, Paradise EM, Ouellet M, Fisher KJ, Newman KL, Ndungu JM, Ho KA, Eachus RA, Ham TS, Kirby J, Chang MC, Withers ST, Shiba Y, Sarpong R, Keasling JD (2006) Production of the antimalarial drug precursor artemisinic acid in engineered yeast. Nature 440(7086):940-943

Rodríguez-Concepción M (2006) Early Steps in Isoprenoid Biosynthesis: multilevel regulation of the supply of common precursors in plant cells. Phytochem Rev 5(1):1-15

Rodriguez-Concepcion M, Boronat A (2002) Elucidation of the methylerythritol phosphate pathway for isoprenoid biosynthesis in bacteria and plastids. A metabolic milestone achieved through genomics. Plant Physiol 130(3):1079-1089

Rohmer M (1999) The discovery of a mevalonate-independent pathway for isoprenoid biosynthesis in bacteria, algae and higher plants. Nat Prod Rep 16(5):565-574

Rohmer M, Knani M, Simonin P, Sutter B, Sahm H (1993) Isoprenoid biosynthesis in bacteria: a novel pathway for the early steps leading to isopentenyl diphosphate. Biochem J 295(Pt 2):517-524

Romano AH, Conway T (1996) Evolution of carbohydrate metabolic pathways. Res Microbiol 147(6-7):448-455

Schrader J, Bohlmann J (2015) Biotechnology of Isoprenoids. Springer, Swizerland

Schwender J, Seemann M, Lichtenthaler HK, Rohmer M (1996) Biosynthesis of isoprenoids (carotenoids, sterols, prenyl side-chains of chlorophylls and plastoquinone) via a novel pyruvate/glyceraldehyde 3-phosphate non-mevalonate pathway in the green alga Scenedesmus obliquus. Biochem J 316(Pt 1):73-80

Seemann M, Rohmer M (2007) Isoprenoid biosynthesis via the methylerythritol phosphate pathway: GcpE and LytB, two novel iron-sulphur proteins. C R Chim 10(8):748-755

Shi M, Luo X, Ju G, Yu X, Hao X, Huang Q, Xiao J, Cui L, Kai G (2014) Increased accumulation of the cardio-cerebrovascular disease treatment drug tanshinone in Salvia miltiorrhiza hairy roots by the enzymes 3-hydroxy-3-methylglutaryl CoA reductase and 1-deoxyD-xylulose 5-phosphate reductoisomerase. Funct Integr Genomics 14(3):603-615

Shiba Y, Paradise EM, Kirby J, Ro DK, Keasling JD (2007) Engineering of the pyruvate dehydrogenase bypass in Saccharomyces cerevisiae for highlevel production of isoprenoids. Metab Eng 9(2):160-168
Sivy TL, Fall R, Rosenstiel TN (2011) Evidence of isoprenoid precursor toxicity in Bacillus subtilis. Biosci Biotechnol Biochem 75(12):2376-2383

Stermer BA, Bostock RM (1987) Involvement of 3-hydroxy-3-methylglutaryl coenzyme a reductase in the regulation of sesquiterpenoid phytoalexin synthesis in potato. Plant Physiol 84(2):404-408

Stermer BA, Bianchini GM, Korth KL (1994) Regulation of HMG-CoA reductase activity in plants. J Lipid Res 35(7):1133-1140

Sugden C, Donaghy PG, Halford NG, Hardie DG (1999) Two SNF1-related protein kinases from spinach leaf phosphorylate and inactivate 3-hydroxy3-methylglutaryl-coenzyme A reductase, nitrate reductase, and sucrose phosphate synthase in vitro. Plant Physiol 120(1):257-274

Sun Z, Cunningham FX Jr, Gantt E (1998) Differential expression of two isopentenyl pyrophosphate isomerases and enhanced carotenoid accumulation in a unicellular chlorophyte. Proc Natl Acad Sci USA 95(19):11482-11488

Tarkowska D, Strnad M (2018) Isoprenoid-derived plant signaling molecules: biosynthesis and biological importance. Planta 247(5):1051-1066

Tholl D (2015) Biosynthesis and biological functions of terpenoids in plants. Adv Biochem Eng Biotechnol 148:63-106

Tippmann S, Chen Y, Siewers V, Nielsen J (2013) From flavors and pharmaceuticals to advanced biofuels: production of isoprenoids in Saccharomyces cerevisiae. Biotechnol J 8(12):1435-1444

Tsuruta H, Paddon CJ, Eng D, Lenihan JR, Horning T, Anthony LC, Regentin R, Keasling JD, Renninger NS, Newman JD (2009) High-level production of amorpha-4,11-diene, a precursor of the antimalarial agent artemisinin, Escherichia coli. PLoS ONE 4(2):e4489

Vadali RV, Fu Y, Bennett GN, San KY (2005) Enhanced lycopene productivity by manipulation of carbon flow to isopentenyl diphosphate in Escherichia coli. Biotechnol Prog 21(5):1558-1561

van Herpen TW, Cankar K, Nogueira M, Bosch D, Bouwmeester HJ, Beekwilder J (2010) Nicotiana benthamiana as a production platform for artemisinin precursors. PLoS ONE 5(12):e14222

Vannice JC, Skaff DA, Keightley A, Addo JK, Wyckoff GJ, Miziorko HM (2014) Identification in Haloferax volcanii of phosphomevalonate decarboxylase and isopentenyl phosphate kinase as catalysts of the terminal enzyme reactions in an archaeal alternate mevalonate pathway. J Bacteriol 196(5):1055-1063

Vickery CR, La Clair JJ, Burkart MD, Noel JP (2016) Harvesting the biosynthetic machineries that cultivate a variety of indispensable plant natural products. Curr Opin Chem Biol 31:66-73

Vinokur JM, Korman TP, Cao Z, Bowie JU (2014) Evidence of a novel mevalonate pathway in archaea. Biochemistry 53(25):4161-4168

Wang F, Lv X, Xie W, Zhou P, Zhu Y, Yao Z, Yang C, Yang X, Ye L, Yu H (2017) Combining gal $4 \mathrm{p}$-mediated expression enhancement and directed evolution of isoprene synthase to improve isoprene production in Saccharomyces cerevisiae. Metab Eng 39:257-266

Waygood EB, Mort JS, Sanwal BD (1976) The control of pyruvate kinase of Escherichia coli. Binding of substrate and allosteric effectors to the enzyme activated by fructose 1,6-bisphosphate. Biochemistry 15(2):277-282

Withers ST, Gottlieb SS, Lieu B, Newman JD, Keasling JD (2007) Identification of isopentenol biosynthetic genes from Bacillus subtilis by a screening method based on isoprenoid precursor toxicity. Appl Environ Microbiol 73(19):6277-6283

Xiao Y, Chu L, Sanakis Y, Liu P (2009) Revisiting the IspH catalytic system in the deoxyxylulose phosphate pathway: achieving high activity. J Am Chem Soc 131 (29):9931-9933

Yang J, Guo L (2014) Biosynthesis of beta-carotene in engineered E. coli using the MEP and MVA pathways. Microb Cell Fact 13:160

Yang C, Gao X, Jiang Y, Sun B, Gao F, Yang S (2016) Synergy between methylerythritol phosphate pathway and mevalonate pathway for isoprene production in Escherichia coli. Metab Eng 37:79-91

Yoon SH, Kim JE, Lee SH, Park HM, Choi MS, Kim JY, Lee SH, Shin YC, Keasling JD, Kim SW (2007) Engineering the lycopene synthetic pathway in E. coli by comparison of the carotenoid genes of Pantoea agglomerans and Pantoea ananatis. Appl Microbiol Biotechnol 74(1):131-139

Yoon SH, Lee SH, Das A, Ryu HK, Jang HJ, Kim JY, Oh DK, Keasling JD, Kim SW (2009) Combinatorial expression of bacterial whole mevalonate pathway for the production of $\beta$-carotene in E. coli. J Biotechnol 140(3-4):218-226 
You S, Yin Q, Zhang J, Zhang C, Qi W, Gao L, Tao Z, Su R, He Z (2017) Utilization of biodiesel by-product as substrate for high-production of $\beta$-farnesene via relatively balanced mevalonate pathway in Escherichia coli. Bioresour Technol 243:228-236

Zepeck F, Grawert T, Kaiser J, Schramek N, Eisenreich W, Bacher A, Rohdich F (2005) Biosynthesis of isoprenoids purification and properties of IspG protein from Escherichia coli. J Org Chem 70(23):9168-9174
Zhao Y, Yang J, Qin B, Li Y, Sun Y, Su S, Xian M (2011) Biosynthesis of isoprene in Escherichia coli via methylerythritol phosphate (MEP) pathway. Appl Microbiol Biotechnol 90(6):1915-1922

Zurbriggen A, Kirst H, Melis A (2012) Isoprene production via the mevalonic acid pathway in Escherichia coli (Bacteria). BioEnergy Res 5(4):814-828

\section{Submit your manuscript to a SpringerOpen ${ }^{\circ}$ journal and benefit from:}

- Convenient online submission

- Rigorous peer review

- Open access: articles freely available online

- High visibility within the field

- Retaining the copyright to your article

Submit your next manuscript at $\boldsymbol{\nabla}$ springeropen.com 